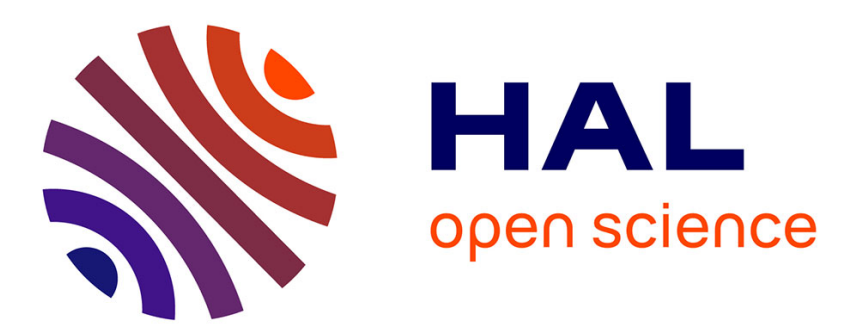

\title{
XPS study of Ni-base alloys oxide films formed in primary conditions of pressurized water reactor
}

Loic Marchetti, Frédéric Miserque, Stéphane Perrin, Michèle Pijolat

\section{To cite this version:}

Loic Marchetti, Frédéric Miserque, Stéphane Perrin, Michèle Pijolat. XPS study of Ni-base alloys oxide films formed in primary conditions of pressurized water reactor. Surface and Interface Analysis, 2015, 47 (5), pp.632-642. 10.1002/sia.5757 . hal-01134217

\section{HAL Id: hal-01134217 https://hal.science/hal-01134217}

Submitted on 5 May 2015

HAL is a multi-disciplinary open access archive for the deposit and dissemination of scientific research documents, whether they are published or not. The documents may come from teaching and research institutions in France or abroad, or from public or private research centers.
L'archive ouverte pluridisciplinaire HAL, est destinée au dépôt et à la diffusion de documents scientifiques de niveau recherche, publiés ou non, émanant des établissements d'enseignement et de recherche français ou étrangers, des laboratoires publics ou privés. 


\title{
XPS study of Ni-base alloys oxide films formed in primary water conditions of pressurized water reactor
}

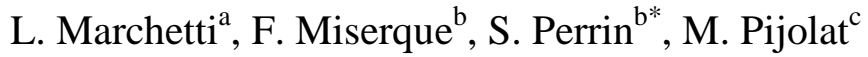

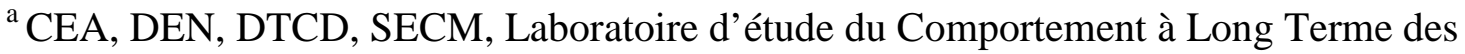 \\ matériaux de conditionnement, F-30207 Bagnols-sur-Cèze, France \\ ${ }^{\mathrm{b}}$ CEA, DEN, DPC, SCCME, Laboratoire d'Etude de la Corrosion Aqueuse, F-91191 Gif-sur- \\ Yvette, France \\ ${ }^{\mathrm{c}}$ Ecole Nationale Supérieure des Mines, centre SPIN, Département PRESSIC, UMR \\ CNRS 5307-LGF, 158 Cours Fauriel, F-42023 Saint-Etienne, France \\ * Corresponding author: F. Miserque
}

CEA Saclay, DEN/DANS/DPC/SCCME, Laboratoire d'Etude de la Corrosion Aqueuse, Bâtiment 458 - PC 50, 91191 GIF sur YVETTE Cedex, France.

Tel.: +3316908 16 19; Fax: +33169081586.

E-mail address: frederic.miserque@cea.fr

\begin{abstract}
The oxide scales formed on alloy 690 during it exposure to PWR primary simulated media at $325^{\circ} \mathrm{C}$ for different periods of time, ranging between $24 \mathrm{~h}$ and $858 \mathrm{~h}$, have been characterized through XPS analysis. These results have been compared to the data obtained on $\mathrm{Cr}_{2} \mathrm{O}_{3}$, $\mathrm{NiCr}_{2} \mathrm{O}_{4}, \mathrm{NiFe}_{2} \mathrm{O}_{4}$ and $\mathrm{Ni}(\mathrm{OH})_{2}$ reference compounds.

This comparison leads to the following conclusions about the scale formed on alloy 690: (i) the deconvolution of $\mathrm{Cr}-2 p_{3 / 2}$ core level spectra seem to show that the internal oxide scale is made of a mix of chromite and chromia, (ii) the evolution of the height ratio between satellite and principal peaks, on the $\mathrm{Ni}-2 p_{3 / 2}$ core level has highlighted the presence of nickel hydroxide for all corrosion durations; and (iii) XPS analysis can be used to study the kinetics of nickel ferrite precipitation. In order to obtain a more complete description of such oxide scales based upon XPS measurements, reference data, obtained on nickel ferrites and chromites in which $\mathrm{Fe}$ is partially substituted to $\mathrm{Ni}$, are needed.

The comparison of published data and reference spectra performed in this work also lead to conclude that core level fits are dependent on the energy resolution which can be achieved with specific spectrometer and analysis procedures. Therefore reference compound spectra need to be recorded in the very identical analytical configuration before dealing with results obtained on corroded specimen.
\end{abstract}

Keywords: nickel base alloys, PWR primary media, oxide scale, XPS, chemical states, Ni and $\mathrm{Cr}$ oxides reference spectra

\section{1- Introduction}

Nickel base alloys such as alloys 600 and 690 are two materials used in the manufacturing of steam generator (SG) tubes in pressurised water reactors (PWR). Under operating conditions, these tubes are corroded in the PWR primary medium, i.e. water at high temperature (about $285-325^{\circ} \mathrm{C}$ ) and high pressure (about 155 bar) containing boron, lithium, and dissolved 
hydrogen. The oxide scale formed during this corrosion phenomenon plays a key role in two degradation processes well known by PWR operators: (i) nickel release from the material during the corrosion process and its subsequent activation into radioactive cobalt in the reactor core, thereby increasing the overall radioactivity of the primary circuit, and (ii) the initiation of stress corrosion cracking (SCC) in SG tubes which induces a decrease in SG thermal exchange efficiency.

The oxide scales formed on nickel base alloys exposed to high temperature hydrogenated water (ranging from $285^{\circ} \mathrm{C}$ to $360{ }^{\circ} \mathrm{C}$ ), in order to simulate corrosion phenomena in PWR primary medium, have always been described as a multilayer structure ${ }^{[1-17]}$.

For very short exposure times (a few minutes) of alloy 600 at $325^{\circ} \mathrm{C}$ in hydrogenated water (2 $\mathrm{mg} / \mathrm{L} \mathrm{Li}, 1200 \mathrm{mg} / \mathrm{L} \mathrm{B}, \mathrm{P}\left(\mathrm{H}_{2}\right)=0.3$ bar and $\left.\mathrm{pH}=7.1\right)$, Machet et al. ${ }^{[1]}$ describe, mainly on the basis of X-ray Photoelectron Spectroscopy (XPS) analysis, a duplex oxide scale composed of an internal $\mathrm{Cr}_{2} \mathrm{O}_{3}$ layer and an external layer comprised of $\mathrm{Ni}(\mathrm{OH})_{2}$. These results are consistent with those reported in Ref. [2] obtained by XPS analysis of alloy 600 exposed for 2 hours in aqueous water at $285^{\circ} \mathrm{C}\left(\mathrm{P}\left(\mathrm{H}_{2}\right)=1\right.$ bar and $\left.\mathrm{pH}=7\right)$.

For longer exposure times (100 hours) in high purity hydrogenated water $\left(\mathrm{P}\left(\mathrm{H}_{2}\right)=1\right.$ bar) at $360{ }^{\circ} \mathrm{C}$, Angeliu and Was ${ }^{[3]}$ studied the oxides formed on model alloys, with compositions close to those of alloys 600 and 690, by XPS and Transmission Electron Microscopy (TEM). They reported the same type of duplex oxide scale: $\mathrm{Ni}(\mathrm{OH})_{2}$ surmounting $\mathrm{Cr}_{2} \mathrm{O}_{3}$. For the same exposure duration of alloy 600 in hydrogenated water at $325^{\circ} \mathrm{C}(2 \mathrm{mg} / \mathrm{L} \mathrm{Li}, 1200 \mathrm{mg} / \mathrm{L} \mathrm{B}$, $\mathrm{P}\left(\mathrm{H}_{2}\right)=0.3$ bar and $\left.\mathrm{pH}=7.1\right)$, Machet et al. ${ }^{[4]}$ also observed, through XPS analysis, this same type of oxide scale.

However, in an earlier paper, Machet et al. ${ }^{[5]}$ studied, using Scanning Electron Microscopy (SEM) and XPS techniques, the oxide scale formed on alloy 600 in the same conditions for exposure times ranging from 50 to 400 hours. They observed, (i) an outer layer composed of well-defined octahedral crystals rich in $\mathrm{Fe}$, and (ii) an inner layer rich in chromium in which $\mathrm{N}_{\mathrm{Cr}} / \mathrm{N}_{\mathrm{Ni}}$ ratio is close to 2, which is in good agreement with the presence of $\mathrm{NiCr}_{2} \mathrm{O}_{4}$.

These last results are much more consistent with the results published by Carrette et al. ${ }^{[6-7]}$, who have exposed alloy 690 to high temperature $\left(325^{\circ} \mathrm{C}\right)$ hydrogenated water $(2 \mathrm{ppm} \mathrm{Li}$, $1000 \mathrm{ppm} \mathrm{B}, \mathrm{P}\left(\mathrm{H}_{2}\right) \approx 0.2$ bar and $\mathrm{pH}=7.3$ ) for durations ranging between 24 and 2160 hours. The oxidized samples were studied employing a set of characterisation techniques including SEM, TEM, XPS, Secondary Ion Mass Spectrometry (SIMS) and Grazing Incidence X-Ray Diffraction (GIXRD). The external oxide layer is described as being comprised of hydroxide and $\mathrm{NiFe}_{2} \mathrm{O}_{4}$ or $\mathrm{NiCr}_{2} \mathrm{O}_{4}$, depending on media saturation, while the internal oxide seems to be $\mathrm{Cr}_{2} \mathrm{O}_{3}$.

Others results obtained, by SEM, TEM, GIXRD and SIMS mainly, on alloys $600{ }^{[8-10]}$ or 690 ${ }^{[8-9]}$ exposed to hydrogenated water at $360{ }^{\circ} \mathrm{C}\left(2 \mathrm{ppm} \mathrm{Li}, 1200\right.$ or $1000 \mathrm{ppm} \mathrm{B}$ and $\mathrm{P}\left(\mathrm{H}_{2}\right)=0.3$ or 0.17 bar respectively in Ref. $[8,10]$ or [9]) dealt with an external scale made of $\mathrm{Fe}$ and $\mathrm{Ni}$ rich spinel oxide and an internal oxide rich in $\mathrm{Cr}$. These last papers are in good agreement with the description made by Carrette et al. ${ }^{[6-7]}$.

It is clear, from the presented literature review, that the nature of the passive film formed on nickel-base alloys in PWR primary simulated media is still a controversial subject and must be further studied using a combination of characterisation techniques in order to obtain a satisfactory description.

In previous papers ${ }^{[11-13]}$, we investigated the structure of the oxide layers formed on nickelbased alloys (alloys 600 and 690) in PWR primary medium by SEM and TEM ${ }^{[11-12]}$ as well as by photoelectrochemical techniques (PEC) ${ }^{[13]}$. These studies have led us to propose an oxide layer divided into two major parts: an external layer composed of nickel ferrite $\left(\mathrm{Ni}_{(1-}\right.$ 
$\left.{ }_{\text {z) }} \mathrm{Fe}_{(2+z)} \mathrm{O}_{4}\right)$ and nickel hydroxide, formed by precipitation phenomena ${ }^{[12]}$ and an internal layer mainly composed of a continuous spinel of a mixed iron and nickel chromite $\left(\mathrm{Ni}_{11}\right.$

${ }_{x)} \mathrm{Fe}_{\mathrm{x}} \mathrm{Cr}_{2} \mathrm{O}_{4}$ ). Furthermore, nodules of $\mathrm{Cr}_{2} \mathrm{O}_{3}$, with a size about $5 \mathrm{~nm}$, were uniformly distributed at the interface between this internal spinel layer and the alloy. A scheme of this proposed scale is presented in figure 1.

In PWR primary conditions, the thickness of the internal scale varies from one nanometer to several tens of nanometers depending on the experimental conditions (surface state, duration...) ${ }^{[4-5,14-15]}$. In this range of thicknesses, XPS seems to be a promising way to improve the description of this oxide scale.

Nevertheless, it must be remembered that in this type of system, i.e. a mixture of different $\mathrm{Fe}$, $\mathrm{Ni}$ and Cr oxides, the interpretation of the shape of XPS spectra, in terms of chemical state, is complicated, notably by (i) the emergence of "shake-up" satellite peaks superimposed to the primary structure of the $\mathrm{Ni}-2 p$ core levels ${ }^{[18-20]}$ and (ii) the existence of a multiplet structure on the $\mathrm{Cr}-2 p$ core levels ${ }^{[21-22]}$. Indeed, after the photoemission of a core electron, there is a finite probability that the ion would be left in an excited state. In the case of transition metals (and notably for nickel), this excited state correspond to an electronic transition toward the unfilled $3 d$ shell. When the ion is left in this state, the kinetic energy of the photoelectron is reduced by the energy needed for this electronic transition, which leads to the emergence of a "shake-up" satellite at a binding energy higher than the main peak. Multiplet splitting is the consequence of interactions between the core electron hole resulting from the photoemission process (on the $2 p$ level in the case of first row transition metals), and the unpaired electrons in the $3 d$ shell. These interactions can create a number of final states which can emerge on the photoelectron spectrum. Moreover, for conductive metals as $\mathrm{Cr}$ or $\mathrm{Ni}$, there is an enhanced probability that the emitted photoelectron loses kinetic energy by interaction with conduction electrons. These losses are weak and result in an asymmetry of the main peak toward high binding energy values.

In this context, the aim of this paper is, first, to study the structure of XPS spectra performed on reference compounds of $\mathrm{Ni}$ and $\mathrm{Cr}$ oxide or hydroxide and to compare the obtained results with literature data. Then, XPS analysis will be performed on the alloy 690 samples that have been exposed to PWR primary simulated medium; these samples have been previously analyzed by TEM and PEC ${ }^{[11-13]}$. Lastly, XPS results obtained on these samples will be discussed in the light of (i) those performed on reference compounds and (ii) samples characterizations previously performed.

\section{2- Materials and methods}

\section{2-1- References compounds}

Five reference compounds have been analyzed by XPS: $\mathrm{Ni}^{0}, \mathrm{Ni}(\mathrm{OH})_{2}, \mathrm{Cr}_{2} \mathrm{O}_{3}, \mathrm{NiFe}_{2} \mathrm{O}_{4}$ and $\mathrm{NiCr}_{2} \mathrm{O}_{4}$.

The $\mathrm{NiFe}_{2} \mathrm{O}_{4}$ and $\mathrm{NiCr}_{2} \mathrm{O}_{4}$ powders used as reference samples were $>99 \%$ pure and were respectively supplied by Alfa Aesar and IoLiTec GmbH. These powders were characterized by XRD and correspond respectively with JCPDS files \#10-0325 and \#1-075-1728 (not shown). 
In order to make the $\mathrm{Cr}_{2} \mathrm{O}_{3}$ reference sample, a chromium plate supplied by Goodfellow (99.99\% in purity) was used. The sample, in the form of $1 \mathrm{~mm}$ thick sheets, was mirrorpolished with $\mathrm{SiC}$ paper up to grade 1200 , diamond paste up to $1 \mu \mathrm{m}$ and alumina gel finished.

This sample was then oxidized for 6 hours at $900{ }^{\circ} \mathrm{C}$ under a 1 bar Ar- $20 \% \mathrm{O}_{2}$ mixed atmosphere. The scale was analysed by GIXRD (not shown here) and identified as $\mathrm{Cr}_{2} \mathrm{O}_{3}$ (JCPDS file \#38-1479).

A nickel sheet supplied by Goodfellow, $99.999 \%$ in purity, was used to prepare de $\mathrm{Ni}^{0}$ and $\mathrm{Ni}(\mathrm{OH})_{2}$ reference samples. Plate samples, $1 \mathrm{~mm}$ thick, were mirror-polished with $\mathrm{SiC}$ paper up to grade 1200 , diamond paste up to $1 \mu \mathrm{m}$, and alumina gel finished.

In order to make $\mathrm{Ni}^{0}$ reference spectra, this type of sample is introduced in the spectrometer and in situ cleaned by $\mathrm{Ar}^{+}$sputtering prior to XPS analysis in order to remove the native oxide layer and any surface contamination.

For the preparation of a $\mathrm{Ni}(\mathrm{OH})_{2}$ reference sample, a nickel sheet was used as a working electrode in a classical three-electrode electrochemical cell. The reference electrode was a saturated calomel electrode and the counter-electrode was a platinum grid. The electrolyte

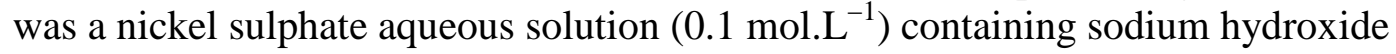
adjunction $(\mathrm{pH}=12)$. This solution was maintained under an atmosphere of 1 bar $\mathrm{O}_{2}$ at 90 ${ }^{\circ} \mathrm{C}$. The open circuit potential was measured to $-200 \mathrm{mV} / \mathrm{SCE}$ and the working electrode was then anodically polarized at $-100 \mathrm{mV} / \mathrm{SCE}$ for 24 hours. Under these conditions the stable solid phase, $\beta-\mathrm{Ni}(\mathrm{OH})_{2}{ }^{[23]}$, is expected to grow at the surface of the working electrode. This reference sample was only analysed by XPS because of the thinness of the grown oxide scale and the obtained results were compared to literature data.

\section{2-2- Corrosion tests performed in PWR primary simulated medium}

The Ni base alloy used in this study is the alloy 690. Its composition is given in table 1. Coupons $(30 \times 20 \times 2.5 \mathrm{~mm})$ were mechanically mirror-polished with $\mathrm{SiC}$ paper up to grade 1200 , diamond paste up to $1 \mu \mathrm{m}$ and alumina gel finished. Specimens were rinsed in an ethanol-acetone binary mixture in ultrasonic bath and dried.

Seven corrosion durations were investigated $(24$ h, 48 h, 66 h, 164 h, 304 h, 406 h and 858 h). All corrosion experiments were performed at $325^{\circ} \mathrm{C}$, under 155 bar in a recirculation autoclave with a flow rate of $17 \mathrm{~L} \cdot \mathrm{h}^{-1}$. This testing device has previously been detailed in Ref. [12]. The aqueous solution contained 2 ppm lithium (LiOH) and 1000 ppm boron $\left(\mathrm{H}_{3} \mathrm{BO}_{3}\right)$ in equilibrium with a hydrogen overpressure of $0.29 \pm 0.02$ bar. This overpressure ensures a dissolved $\mathrm{H}_{2}$ concentration of $1.310^{-3} \mathrm{~mol} . \mathrm{L}^{-1}$ at $325^{\circ} \mathrm{C}$ (corresponding to a molar fraction of $\left.3.410^{-5}\right)$ and a low oxygen content $\left(\mathrm{O}_{2}<10 \mathrm{ppb}\right)$.

The recirculation loop used in this work is equipped with ion-exchange resins. The aim of this device is to maintain the concentration of metallic cations in the liquid phase as low as possible to avoid precipitation. Their efficiency is much dependent on the temperature. Optimizations have led to their use at $20^{\circ} \mathrm{C}$. However, experiments with two durations (164 $\mathrm{h}$ and $858 \mathrm{~h}$ ) were carried out under so-called "damaged conditions", i.e. at $32{ }^{\circ} \mathrm{C}$, temperature for which the ion-exchange resins efficiency was lower.

\section{2-3- Oxide scale characterizations}


Two SEM have been used for the observation of the oxide scales: a LEO 1450VP and a Karl Zeiss 1525 equipped with a Field Emission Gun (FEG).

XPS analyses on reference compounds and corroded samples were carried out with Thermofisher Escalab 220i XL and 250 XI using a monochromatic Al K $\alpha$ source (10 mA, 20 $\mathrm{kV}$ ). Due to an important charge effect the powder reference samples were analysed using a charge compensation flood gun. The instrument was calibrated to the silver Fermi level $(0 \mathrm{eV})$ and to the $3 d_{5 / 2}$ core level of metallic silver $(368.3 \mathrm{eV})$. The $\mathrm{C}-1 s$ signal for adventitious carbon was used to correct the charge effect. The C-C/C-H component of C- $1 s$ spectra was fixed at $285.0 \mathrm{eV}$. The analysis zone was $\sim 1 \times 1 \mathrm{~mm}^{2}$ for the monochromatic source. The pass energy for overview and high resolution spectra was $100 \mathrm{eV}$ and $20 \mathrm{eV}$, respectively. The data processing was performed using the commercial Avantage software. For the fitting procedure, a Shirley background has been used and Lorentzian-Gaussian $(\mathrm{L} / \mathrm{G})$ ratio was fixed at $30 \%$.

\section{3- Results and discussion}

The data collected in the literature on the $\mathrm{Cr}-2 p_{3 / 2}, \mathrm{Ni}-2 p_{3 / 2}$ and $\mathrm{O}-1 s$ core levels, as well as the results obtained by analyzing the same core levels on reference compounds or corroded samples are presented in this section in order to identify the chemical state of $\mathrm{Cr}, \mathrm{Ni}$ and $\mathrm{O}$ in the oxide scale formed. The chemical state of $\mathrm{Fe}$, also present in the oxide, was not investigated, neither on its $2 p_{3 / 2}$ core level because of the overlapping of nickel Auger peaks due to acquisition conditions, nor on its $2 p_{1 / 2}$ core level because of the lack of published data. Nevertheless, the acquisitions of the $2 p_{1 / 2}$ core level of Fe have been used in order to compare (i) the relative intensities of Fe on XPS spectra to (ii) precipitation phenomena observed by SEM for different exposure durations (see subsection 3-2-2).

\section{3-1- Comparison between literature data and XPS analyses performed on reference compounds for the identification of chemical state on $\mathrm{Ni}-2 p_{3 / 2}, \mathrm{Cr}-2 p_{3 / 2}$ and $\mathrm{O}-1 s$ core levels}

Besides the binding energy (BE), many different parameters have been used for the analysis of XPS spectra in order to differentiate two compounds. These parameters include, but are not limited to: (i) mathematical parameters defining an asymmetric peak, (ii) the full width at half maximum (FWHM) of a peak, and (iii) the peak intensity ratios observed on the same core level, expressed as the part of one peak in the total area of a core level envelope or the height ratio between two peaks.

In this section, the comparison of reported data is limited to binding energies and peak intensity ratios because the FWHM values strongly depend of the spectrometer and implemented acquisition conditions. However, when asymmetric peaks were used in order to fit XPS spectra, particularly in the case of the metallic Ni or Cr core levels, this factor is mentioned even if the peak shape parameters published were not reported.

Moreover, for all peak positions reported in the literature and discussed below, the $\mathrm{C}-\mathrm{C} / \mathrm{C}-\mathrm{H}$ component of C- $1 s$ spectra was fixed at $285.0 \mathrm{eV}$ when this datum is mentioned in the cited article. When it is not the case, this is clearly noticed in the text.

\section{3-1-1- Identification of the chemical state on the $\mathrm{Ni}-2 p_{3 / 2}$ core level for different nickel compounds}


The study of chemical state on the Ni-2 $2 p_{3 / 2}$ core level is difficult because of the emergence of satellite peaks superimposed on the primary structure of the spectra ${ }^{[1,18-20]}$. The use of multiplet structures for assignment of $\mathrm{Ni}-2 p$ spectral profiles has also been reported, particularly in the case of nickel oxide or hydroxide ${ }^{[20,24-25]}$.

In order to compare with literature data discussed more in details below, $\mathrm{Ni}-2 p_{3 / 2}$ core level spectra recorded in this work on various reference compounds are shown in figure 2.

From Refs. [20, 24-25], the spectra of metallic nickel can be fitted using 3 peaks: a main asymmetric peak at $852.6 \mathrm{eV}$ which represents roughly $80 \%$ of the total area of the core level, and two broader satellites peaks with $\mathrm{BE}$ near $3.7 \mathrm{eV}$ and $6.1 \mathrm{eV}$ above the main contribution, respectively for the minor (less than $7 \%$ of the total area of the core level) and the major (ranging between 12 to $15 \%$ of the total area) ones.

The spectrum obtained here for metallic $\mathrm{Ni}$ is shown in figure $2(\mathrm{a})$. The $\mathrm{Ni}-2 p_{3 / 2}$ main peak (BE at $852.6 \mathrm{eV}$ ) highlights an asymmetry on the high binding energy side and is linked to a shake-up satellite peak ( $6.3 \mathrm{eV}$ above the main contribution). The fitting parameters found on this spectra (BE, asymmetry of the main peak, intensity ratio between the main and the satellite peaks) are consistent with literature data. Nevertheless, only the satellite peak found at roughly $6 \mathrm{eV}$ above the main peak component has been used in the fitting procedure. It can be pointed out that depending on the parameters used to fit the asymmetric main peak, the minor satellite reported in literature can be covered by the main contribution.

The spectra of $\mathrm{NiO}$ can be fitted using a multiplet structure of five peaks. The two highest peaks with regards to $\mathrm{BE}$ (i.e. 864.2 and $866.5 \mathrm{eV}$ ) each represent less than $4 \%$ of the total area of the core level ${ }^{[24-25]}$. Regarding the three main contributions, they peaked at $853.9 \mathrm{eV}$, $855.6 \mathrm{eV}$ and $861.1 \mathrm{eV}$. Furthermore, by considering only the spectrum envelope of the $2 p_{3 / 2}$ core level, the $853.9 \mathrm{eV}$ and $855.6 \mathrm{eV}$ peaks form a doublet of peaks, with two identifiable maxima, on spectra reported in Refs. [20,24] which seems to be characteristic of the presence of $\mathrm{NiO}$.

Considering (i) this distinctive characteristic and (ii) that NiO growth on nickel base alloys exposed to primary water is not expected at the concentration of dissolved hydrogen studied in this work, no reference compound of this oxide was analyzed.

As for $\mathrm{NiO}$, the $\mathrm{Ni}-2 p_{3 / 2}$ core level of $\mathrm{NiFe}_{2} \mathrm{O}_{4}$ have been fitted with a multiplet structure of five peaks ${ }^{[25]}$ : two minor peaks at $864.9 \mathrm{eV}$ and $867.2 \mathrm{eV}$ (less than $4 \%$ of the total area of the envelope for each one) and three main ones, which peaked at $854.7 \mathrm{eV}, 856.2 \mathrm{eV}$ and $861.6 \mathrm{eV}$. By comparison with the case of $\mathrm{NiO}$, the three main peaks are shifted toward higher $\mathrm{BE}$ and the envelope of the core level published by Biesinger et al. ${ }^{[25]}$ for $\mathrm{NiFe}_{2} \mathrm{O}_{4}$ exhibit a partial superimposition of the peak components at $854.7 \mathrm{eV}$ and $856.2 \mathrm{eV}$ leading to a shoulder toward high energies on the spectrum, instead of the $\mathrm{NiO}$ doublet of peaks. It can be interesting to note that in 1975 , McIntyre and Cook ${ }^{[18]}$ published a less accurate spectrum for the Ni-2 $p_{3 / 2}$ core level of $\mathrm{NiFe}_{2} \mathrm{O}_{4}$ which exhibits only two peaks: a principal contribution at $855.3 \mathrm{eV}$ and a satellite band at higher BE (evaluated at roughly $862 \mathrm{eV}$ on the basis of the published spectrum, but this last value is not reported in the original article). It can then be supposed that the satellite component identified in Ref. [18] matches with the broad one reported at $861.6 \mathrm{eV}$ in Ref. [25]. In the same way, the main contribution reported in Ref. [18] (855.3 eV) can correspond to the two partially superimposed ones (respectively at $854.7 \mathrm{eV}$ and $856.2 \mathrm{eV}$ ) identified by Biesinger et al. ${ }^{[25]}$. This last remark should explain why spectra obtained on a same compound can be fitted with more or less peaks in the literature, depending, in this case, on the energy resolution associated with the spectra acquisition. 
With our energy resolution, five peaks can be distinguished on the $\mathrm{Ni}-2 p_{3 / 2}$ core level recorded on the $\mathrm{NiFe}_{2} \mathrm{O}_{4}$ reference compound (figure 2(b)): (i) two partially superimposed one at $855.3 \mathrm{eV}$ and $856.8 \mathrm{eV}$ resulting in a shoulder toward high energies on the envelope, (ii) a broader shake-up satellite peak at $862.0 \mathrm{eV}$ and (iii) two minor contributions at $865.7 \mathrm{eV}$ and $868.0 \mathrm{eV}$ respectively. These results are in overall good agreement with the literature data mentioned above.

The methods of deconvolution reported in literature concerning the fit of $\mathrm{NiCr}_{2} \mathrm{O}_{4}$ spectra also differ in the many published works. In Refs. [26-27], the Ni- $2 p_{3 / 2}$ core level of this oxide is fitted with two peaks: a main contribution which peaked in the $856-856.5 \mathrm{eV}$ range (note that in these two articles, the $\mathrm{BE}$ of the $\mathrm{C}-\mathrm{C} / \mathrm{C}-\mathrm{H}$ component of $\mathrm{C} 1 \mathrm{~s}$ spectra is not reported) and a satellite one between $5.1 \mathrm{eV}$ and $5.35 \mathrm{eV}$ above the principal peak. These articles also reported the height ratio of the satellite to principal peaks, which ranges from 0.71 to 0.74 . For the same compound, Biesinger et al. ${ }^{[25]}$ propose a fit using a multiplet structure of six peaks, with three minor contributions at $854 \mathrm{eV}, 861.2 \mathrm{eV}$ and $866.2 \mathrm{eV}$ (respectively $7 \%$, $2.3 \%$ and $6.1 \%$ of the total area of the core level) and three main peaks: (i) two at $856.0 \mathrm{eV}$ and $856.7 \mathrm{eV}$ which are highly superimposed and seem to correspond to the principal peak reported in Refs. [26-27] and (ii) one at $861.5 \mathrm{eV}$ which could correspond to the satellite peak reported by the last authors.

Furthermore, on the spectrum published by Biesinger et al. ${ }^{[25]}$, two features of the envelope could be useful in order to distinguish between $\mathrm{NiCr}_{2} \mathrm{O}_{4}$ and other $\mathrm{Ni}$ oxides: the partial superimposition of the $854 \mathrm{eV}$ and $856 \mathrm{eV}$ peaks lead to a shoulder toward low energies on the spectrum, whereas the minor contribution at $866.2 \mathrm{eV}$ is well separated to the one at 861.5 $\mathrm{eV}$ and produce a slight but clearly observable peak at higher energy values.

The figure 2(c) shows the Ni-2 $p_{3 / 2}$ core level recorded on $\mathrm{NiCr}_{2} \mathrm{O}_{4}$ reference powder. The proposed curve fitting method uses only four contributions, rather than the six peaks proposed by Biesinger et al. ${ }^{[25]}$ : two main peak components located at $856.4 \mathrm{eV}$ and $861.7 \mathrm{eV}$ (corresponding respectively to the main peak and the major shake-up satellite) and two minor ones at $854.2 \mathrm{eV}$ and $866.3 \mathrm{eV}$ in $\mathrm{BE}$. This fitting procedure seems to adequately reproduce the two characteristic features of a $\mathrm{NiCr}_{2} \mathrm{O}_{4}$ envelope spectrum: (i) a shoulder toward low energies on the main peak and (ii) a slight second shake-up satellite above $866 \mathrm{eV}$. It can also be noted that the height ratio of the major satellite to the main peak measured in this work (0.65) is consistent with those reported in Refs. [26-27].

For $\mathrm{Ni}(\mathrm{OH})_{2}$, Machet ${ }^{[28]}$ reported a deconvolution with two peaks: the main one at $\mathrm{BE}$ ranging from $855.7 \mathrm{eV}$ to $857.4 \mathrm{eV}$ and the satellite peak always $5.8 \mathrm{eV}$ above. It is interesting to note the value of the height ratio of the satellite to principal peaks reported in this work (0.3).

Mansour and Melendres ${ }^{[29-31]}$ have also reported a deconvolution with two peaks for the Ni$2 p_{3 / 2}$ core level of $\mathrm{Ni}(\mathrm{OH})_{2}, \mathrm{yH}_{2} \mathrm{O}$, in which the principal component varying between 855.5 $\mathrm{eV}$ and $856.2 \mathrm{eV}$ whereas the satellite one ranging from $861.2 \mathrm{eV}$ to $861.8 \mathrm{eV}$, depending on the hydration state y of the hydroxide.

Moreover, a finer deconvolution have also been proposed, taking into account multiplet splitting on the Ni-2 $p_{3 / 2}$ core level ${ }^{[24-25]}$ in order to fit the $\mathrm{Ni}(\mathrm{OH})_{2}$ spectrum. This fit is made of six peaks: four minor peaks at $855.1 \mathrm{eV}, 857.9 \mathrm{eV}, 860.7 \mathrm{eV}$ and $866.7 \mathrm{eV}$ (each representing less than $7 \%$ of the total area of the envelope) and two major contributions exhibiting $\mathrm{BE}$ of $855.9 \mathrm{eV}$ and $861.7 \mathrm{eV}$ which could respectively correspond to the principal and satellites peaks in the deconvolution using only two peaks reported above.

A two component deconvolution procedure has been used for fitting the $\mathrm{Ni}-2 p_{3 / 2}$ core level spectra recorded on the $\mathrm{Ni}(\mathrm{OH})_{2}$ layer (figure $2(\mathrm{~d})$ ). The major peak is found at a $\mathrm{BE}$ value of 
$856.2 \mathrm{eV}$ whereas a shake-up satellite appears $5.9 \mathrm{eV}$ above. The height ratio of the satellite to the main peak is equal to 0.28 and well agrees with the value reported in Ref [28].

In order to summarize, rather than to deal with a challenging complete multi-component curve fitting, the interpretation of the $2 p_{3 / 2}$ core levels of reference $\mathrm{Ni}$ compounds and it comparison with existing literature data allows us to emphasize a few key deconvolution parameters or spectral features that can be used in order to identify various Ni chemical states in a mixed oxide scale.

Although the $\mathrm{BE}$ values of the main peak cannot be used to distinguish $\mathrm{Ni}(\mathrm{OH})_{2}$ from $\mathrm{NiCr}_{2} \mathrm{O}_{4}$ because they are too close, this parameter allows for the differentiation between metallic $\mathrm{Ni}, \mathrm{NiFe}_{2} \mathrm{O}_{4}$, and the two compounds mentioned above (figure 2).

In order to distinguish between $\mathrm{Ni}(\mathrm{OH})_{2}$ and $\mathrm{NiCr}_{2} \mathrm{O}_{4}$ or a mix of these compounds, the height ratio of the major satellite to the main contribution may be useful; this parameter is very different for these two species (roughly 0.3 and 0.7 for $\mathrm{Ni}(\mathrm{OH})_{2}$ and $\mathrm{NiCr}_{2} \mathrm{O}_{4}$ respectively). In addition, the presence of a weaker satellite peak around $866.3 \mathrm{eV}$ may also indicate the presence of $\mathrm{NiCr}_{2} \mathrm{O}_{4}$.

\section{3-1-2- Identification of the chemical state on the $\mathrm{Cr}-2 p_{3 / 2}$ core level for different chromium compounds}

The spectra of metallic chromium can be fitted using an asymmetric peak with a BE value of $574.4 \mathrm{eV}$ or $574.5 \mathrm{eV}$ according to works published by Biesinger et al. ${ }^{[25]}$ or Halada and Clayton ${ }^{[32]}$.

From Refs. $[22,25]$, the $\mathrm{Cr}-2 p_{3 / 2}$ core level of $\mathrm{Cr}(\mathrm{OH})_{3}$ can also be fitted with a single but symmetric peak, ranging from $577.3 \mathrm{eV}$ to $577.6 \mathrm{eV}$ depending on the hydration state of the compound.

The case of $\mathrm{Cr}_{2} \mathrm{O}_{3}$ deconvolution is more controversial. Some works exhibit a single and asymmetric peak with a $\mathrm{BE}$ value between 576.3 and $576.7 \mathrm{eV}^{[32-33]}$, whereas other studies use a multiplet structure, involving 3 to 5 peaks, in order to fit the $\mathrm{Cr}-2 p_{3 / 2}$ core level of this oxide ${ }^{[21-22,25]}$.

For $\mathrm{NiCr}_{2} \mathrm{O}_{4}$, Sloczynski et al. ${ }^{[27]}$ propose a deconvolution using a single peak at $576.7 \mathrm{eV}$ (note that the $\mathrm{BE}$ of $\mathrm{C}-1 s$ peak component for the adventitious is not reported in this article), whereas Biesinger et al. ${ }^{[22,25]}$, like for $\mathrm{Cr}_{2} \mathrm{O}_{3}$ or $\mathrm{FeCr}_{2} \mathrm{O}_{4}$, fit their spectra by considering multiplet splitting.

For the purpose of this study (i.e. to use XPS in order to better identify the different oxides composing the multilayered scale formed during the corrosion of nickel-base alloys in PWR primary medium), it is interesting to compare the $\mathrm{Cr}-2 p_{3 / 2}$ spectral fitting parameters published in Ref. [25] for $\mathrm{Cr}_{2} \mathrm{O}_{3}, \mathrm{NiCr}_{2} \mathrm{O}_{4}$ and $\mathrm{FeCr}_{2} \mathrm{O}_{4}$, especially because they have been obtained in the same analytical configuration. It can be seen in table 2, that multiplet structure of 4 or 5 peaks has been used to deconvolve the spectra envelope of these oxides. It can be pointed out that the comparison of these deconvolutions for the three oxides mentioned above only exhibit slight differences in $\mathrm{BE}$ and associated contributions to the total area of the Cr$2 p_{3 / 2}$ core level. It can also be seen that the fit of $\mathrm{FeCr}_{2} \mathrm{O}_{4}$ spectra does not involve a fifth peak, in contrast to those of $\mathrm{Cr}_{2} \mathrm{O}_{3}$ and $\mathrm{NiCr}_{2} \mathrm{O}_{4}$; for this last two oxides the fifth peak is only a minor contribution which need a high resolution acquisition to be evidenced. Although these data may be used in order to differentiate between the XPS spectra recorded on chromium 
sesquioxide and nickel or iron chromite, it can be difficult, depending on the energy resolution achieved, to identify each compound in a mixture of these corrosion products when basing analysis uniquely upon the $\mathrm{Cr}-2 p_{3 / 2}$ core level.

The comparison of curve fitting of $\mathrm{Cr}_{2} \mathrm{O}_{3}$ and $\mathrm{NiCr}_{2} \mathrm{O}_{4} \mathrm{Cr}-2 p_{3 / 2}$ core level spectra recorded on reference compounds is shown in figure 3. Even if theoretical modeling of Gupta and Sen ${ }^{\text {[34- }}$ ${ }^{35]}$ predicts a larger number of final states constituting the multiplet splitting structure, the energy resolution, in this work, does not allow the separation of all these final states. The choice of the peak number used to fit the envelope should be coherent with its shape. It is for this reason that in this work the most simplified curve fitting method has been chosen. In order to represent the asymmetrical broad peak shape of multiplet split $\mathrm{Cr}$ (III) species, evidenced in figure 3, a minimum of 3 peaks is needed to fit the resolved envelope shape. The comparisons of (i) the $\mathrm{BE}$ values, (ii) the shape of the envelopes, as well as (iii) the area ratios between the 3 peaks seen in figures 3 (a) and (b) for $\mathrm{Cr}_{2} \mathrm{O}_{3}$ and $\mathrm{NiCr}_{2} \mathrm{O}_{4}$ respectively, leads to the conclusion that $\mathrm{I}_{\text {peak } 1} / \mathrm{I}_{\text {peak } 2}$ is the unique fitting parameters of $\mathrm{Cr}-2 p_{3 / 2}$ that allow a separation of these two oxides by XPS analysis, with the energy resolution achieved in this work. However, in the case of a mixture of these compounds, and particularly for samples corroded in PWR primary media (for which carbon contamination and/or water adsorption are expected to be higher than in the case of reference compounds), it can be difficult to achieve a clear separation of these two oxides.

\section{3-1-3- Identification of the chemical state on the O-1s core level for $\mathrm{Ni}$ and/or $\mathrm{Cr}$ oxides and hydroxides}

Except in the case of $\mathrm{NiO}$, for which a minor peak component ( $2 \%$ of the total area of the O$1 s$ core level) was identified at $533 \mathrm{eV}$ and attributed to absorbed $\mathrm{O}_{2}$ or $\mathrm{H}_{2} \mathrm{O}^{[24-25]}$; whatever the data considered for the deconvolution of the $\mathrm{O}-1 s$ core level of $\mathrm{Ni}$ and/or Cr oxides, at most two peaks were used for fitting. The main ${ }^{[22,24-25]}$ or single ${ }^{[18,27]}$ contribution peak in the 529.5-530.4 eV range is attributed to lattice oxygen. The second peak reported by Biesinger et al. ${ }^{[22,24-25]}$ shows a BE value in the 531.1-532.1 eV range and was attributed by these authors to defective sites within the oxide crystal whereas other works dealt with hydroxide species ${ }^{[36]}$. It could be pointed out that for all $\mathrm{Ni}$ and/or $\mathrm{Cr}$ oxides considered, the contribution of this second peak to the total area of the O- $1 s$ core level ranges between $20 \%$ and $40 \%$.

The O- $1 s$ core level spectra for $\mathrm{Cr}_{2} \mathrm{O}_{3}, \mathrm{NiFe}_{2} \mathrm{O}_{4}$ and $\mathrm{NiCr}_{2} \mathrm{O}_{4}$ obtained on reference oxides are presented in Figure 4(a), (b) and (c) respectively. As observed in literature data, a major contribution is found at a binding energy of around $530 \mathrm{eV}$ for the various oxides. A second contribution at higher binding energies side is also present (at $532.0 \mathrm{eV}$ ). This contribution is attributed to adsorbed $\mathrm{OH}^{[37]}$ or organic oxygen due to contamination.

The spectra obtained on Ni hydroxide can also be deconvolved with two peaks: a main ${ }^{[30]}$ or single ${ }^{[18,24-25,29]}$ contribution with a BE ranging from $531.0 \mathrm{eV}$ to $531.2 \mathrm{eV}$ is attributed to hydroxide ions whereas the appearance of a minor component, peaking at $532.4 \mathrm{eV}^{[30]}$ and attributed to $\mathrm{H}_{2} \mathrm{O}$, depends on the hydration state of the compound.

It is also the case for $\mathrm{Cr}(\mathrm{OH})_{3}$, for which a main peak is evidenced in the $531.4-531.9 \mathrm{eV}$ range and a minor one (exhibited $\mathrm{BE}$ varying from $532.8 \mathrm{eV}$ to $533.6 \mathrm{eV}$ ) is attributed to hydration ${ }^{[22,25]}$.

The O- $1 s$ spectra (Fig. 4(d)) for $\mathrm{Ni}(\mathrm{OH})_{2}$ reference compound is fitted, in this work, using a single contribution at $532.0 \mathrm{eV}$ which enables the separation on $\mathrm{O}-1 s$ core level between lattice oxide and hydroxide. 
Even if the main peak component on O- $1 s$ core level could allow for the differentiation between oxides and hydroxides when analysed separately, in the case of a mixture of corrosion products, the overlap between the hydroxide peak and the second peak of the oxides makes it very difficult to differentiate one compound from another. In this last case, in order to help with the identification of these products, the intensity ratio between these two peak components, as well as the appearance of a third contribution at higher BE (due to the hydration of hydroxides) could bring informations concerning a possible compounds mixing.

As it can be seen in subsections 3-1-1, 3-1-2 and 3-1-3, a lot of spectral fitting parameters can be used for the study of the chemical shifts on XPS spectra recorded on Ni and/or Cr oxides and hydroxides. Even if the published data discussed above exhibit some of these parameters which seem to be relevant in order to distinguish between considered compounds, the diversity of parameters reported could lead to confusing issues when a mixture of corrosion products is analyzed. Moreover, the comparison of data collected in the literature and reference spectra performed in this work seems to evidence that core level fits are dependent, in a particular study, on the energy resolution which can be achieved with specific spectrometer and analysis procedures. That is why, before dealing with results obtained on corroded samples, the acquisition of reference compound spectra performed in the same analytical configuration is needed.

\section{3-2- Application to alloy 690 corroded in PWR primary conditions}

The XPS analysis of the oxide scale formed on alloy 690 corroded in PWR primary simulated water have been led for all exposition durations investigated $(24$ h, 48 h, 66 h, 164 h, 304 h, $406 \mathrm{~h}$ and $858 \mathrm{~h}$ ). Through XPS spectrum deconvolutions, it has been found that the set of corrosion durations can be separated into three classes; one duration from each class will be further discussed in detail. The results obtained for three characteristic exposure durations (24 $\mathrm{h}, 164 \mathrm{~h}$ and $858 \mathrm{~h}$ ) on the $\mathrm{Cr}-2 p_{3 / 2}, \mathrm{Ni}-2 p_{3 / 2}$ and $\mathrm{O}-1 s$ core level spectra are presented in subsection 3-2-1. In the subsection 3-2-2, which deals with the interest of XPS analysis for studying nickel ferrite precipitation phenomena, some results obtained on $\mathrm{Ni}-2 p_{3 / 2}$ and $\mathrm{Fe}$ $2 p_{1 / 2}$ core levels are discussed for the entire set of exposure times.

\section{3-2-1- Evolution of the oxide scale when increasing the exposition time}

The figures 5, 6 and 7 show respectively the evolution of $\mathrm{Cr}-2 p_{3 / 2}, \mathrm{Ni}-2 p_{3 / 2}$ and $\mathrm{O}-1 s$ core level spectra of alloy 690 samples, before exposure and with increasing immersion duration in PWR primary simulated medium.

The Cr- $2 p_{3 / 2}$ and $\mathrm{Ni}-2 p_{3 / 2}$ core level spectra recorded on the surface of alloy 690 samples before immersion are reported in figures 5(a) and 6(a). They exhibit respectively high $\mathrm{Cr}^{0}$ and $\mathrm{Ni}^{0}$ contributions, which is consistent with the thinness of the native oxide film (roughly $2 \mathrm{~nm}$ from Ref. [15]). Moreover, the shape of the Ni-2 $p_{3 / 2}$ core level, characterized on figure 6(a) by a sharp and asymmetric peak linked to a satellite structure ( $6 \mathrm{eV}$ above the main peak) is typical of metallic nickel, indicating that this element is excluded from the native oxide layer. It can also be noted that the $\mathrm{Cr}-2 p_{3 / 2}$ core level spectrum recorded on this sample needs to add a multiplet structure (at higher $\mathrm{BE}$ ) to the $\mathrm{Cr}^{0}$ component in order to fit the shape of the envelope. This result indicates that the native scale is made of chromium oxide and excludes or limits the presence of chromium hydroxide at very low level (see subsection 3-1-2).

As the chemical state of Fe was not investigated in details, the presence of this element in the native oxide film cannot be excluded. 
The O- $1 s$ spectrum presented on figure 7(a) exhibits 3 contributions: (i) one peak component near $530 \mathrm{eV}$ corresponding to oxygen in the oxide lattice, (ii) a minor one at roughly $533.4 \mathrm{eV}$ which is the consequence of water contamination and (iii) the most intense one near $532 \mathrm{eV}$, despite the absence of hydroxide compounds. This last observation highlights the weight of absorbed $\mathrm{OH}$ or organic oxygen, due to contamination, in the $\mathrm{O}-1 s$ core level balance, in the case of thin (i. e. few nanometers) oxide film analysis.

Figures $5(\mathrm{~b})$ to $5(\mathrm{~d})$ summarize the evolution of $\mathrm{Cr}-2 p_{3 / 2}$ core level spectra recorded on corroded alloy 690 with increasing immersion duration. According to the decrease of the $\mathrm{Cr}^{0}$ peak intensity, the thickness of the oxide scale increased with time. On the basis of literature data and reference spectra discussed in subsection 3-1-2, the curve fitting parameters used to interpret $\mathrm{Cr}-2 p_{3 / 2}$ core level presented on figure 5 (and particularly $\mathrm{I}_{\text {peak } 1}$ to $\mathrm{I}_{\text {peak } 2}$ area ratios, which range between 0.56 and 0.62 ) suggest that the oxide scale is composed of a mix of chromite and chromia.

The general evolution of $\mathrm{Ni}-2 p_{3 / 2}$ core level spectra presented on figures $6(\mathrm{~b})$ to $6(\mathrm{~d})$ corroborate the growth of the oxide scale thickness deduced from figure 5: with increasing immersion time, the signal due to Ni containing oxides and/or hydroxides increases in intensity replacing the one due to metallic nickel.

After $24 \mathrm{~h}$ of exposure to PWR primary conditions, in addition to the metallic contribution, a second main peak at $856.2 \mathrm{eV}$ linked to a satellite structure (peaking at $861.8 \mathrm{eV}$ ) can be evidenced. Considering the values of BE discussed in subsection 3-1-1, these two peaks seem to exclude the presence of nickel ferrite and can be attributed to the formation of nickel hydroxide and/or nickel chromite. Considering the measured height ratio of the satellite to principal peaks, it appears that those components cannot be assigned to the growth of $\mathrm{Ni}(\mathrm{OH})_{2}$ only. Indeed, the measure of this ratio is equal to 0.35 which is an intermediate value between those found for $\mathrm{NiCr}_{2} \mathrm{O}_{4}$ and $\mathrm{Ni}(\mathrm{OH})_{2}$ reference compounds ( 0.65 and 0.28 respectively), corroborating the coexistence of these two nickel-containing products on the corroded alloy surface. Moreover, this value is closer to the height ratio obtained from $\mathrm{Ni}(\mathrm{OH})_{2}$ than those measured on $\mathrm{NiCr}_{2} \mathrm{O}_{4}$. This could be a consequence of the Ni hydroxide preponderance in the mixture of corrosion products and therefore might explain why the minor peaks (peaking at $854.3 \mathrm{eV}$ and $866.3 \mathrm{eV}$ ), emphasized by the $\mathrm{NiCr}_{2} \mathrm{O}_{4}$ reference spectra, are not evidenced on figure 6(b).

From the corresponding O- $1 s$ core level spectrum reported on figure 7(b), the large predominance of the contribution located around $532 \mathrm{eV}$ may be equally related to a main formation of $\mathrm{Ni}$ hydroxide compared to chromite but is also, at least partially, due to the balance between the contamination and the thinness of the oxide layer, as emphasized in the case of the initial surface state. It can be added that the $\mathrm{Ni}(\mathrm{OH})_{2}$ seems not to be hydrated: no contribution of water is noticed on the O- $1 s$ spectrum.

In order to fit the Ni- $2 p_{3 / 2}$ core level spectrum obtained on alloy 690 samples after $164 \mathrm{~h}$ of immersion, a supplementary contribution is needed, as it can be seen on figure 6(c), compared to the case of samples immerged $24 \mathrm{~h}$ (figure 6(b)). This contribution emerges at a BE of $855.0 \mathrm{eV}$, close to the main peak component reported for the $\mathrm{NiFe}_{2} \mathrm{O}_{4}$ reference compound in subsection 3-1-1 and corresponding probably to the appearance of nickel ferrite. As it is discussed more in details in subsection 3-2-2, this conclusion is consistent with the monitoring of the recirculation loop, during this corrosion test, under "damaged conditions" (see subsection 2-2-2 for details) leading to a decrease of ion-exchange resins efficiency. 
The value of the height ratio of the satellite to principal peak ( 0.39 on figure $6(\mathrm{c}))$ seems to be also in agreement with the presence of nickel ferrite. As reported previously in subsection 31-1, $\mathrm{NiFe}_{2} \mathrm{O}_{4}, \mathrm{NiCr}_{2} \mathrm{O}_{4}$ and $\mathrm{Ni}(\mathrm{OH})_{2}$ present their major satellite structure at roughly the same BE. The overlapping of these shake-up structures make them undistinguishable in the case of a mixture of these compounds but lead to variations of the satellite to principal peak height ratio, depending of compounds proportions in the mixture.

Considering the increase of this height ratio compared to the case of $24 \mathrm{~h}$ immersion, it can be concluded that the balance of oxide species increase at the expense of nickel hydroxide, but the respective roles of the chromite growth and the ferrite precipitation on this rise cannot be distinguished.

The increased oxide proportion in the scale of corrosion products formed on alloy 690 after $164 \mathrm{~h}$ of immersion, compared to the case of $24 \mathrm{~h}$ exposure test, is corroborated by the respective evolution of the balance between the lattice oxide and the hydroxide contributions, highlighted by the comparison of O-1s core level spectra reported on figures 7(b) and (c).

For the alloy 690 samples corroded during $858 \mathrm{~h}$, metallic contributions are no more observed on the $\mathrm{Cr}-2 p_{3 / 2}$ and $\mathrm{Ni}-2 p_{3 / 2}$ spectra (see figures 5(d) and 6(d) respectively): the oxide layer is thicker than the depth analyzed by XPS. The peak shape of the Ni-2 $p_{3 / 2}$ spectrum is quite similar with the one reported on figure 2(c) for the $\mathrm{NiFe}_{2} \mathrm{O}_{4}$ reference compound. This last point is in good agreement with SEM observations reported in figure 8 and discussed in subsection 3-2-2, which bring out a large increase of both the number of nickel ferrite crystallites per surface unit and the crystallite size, for this corrosion test.

Nevertheless, samples exposed $858 \mathrm{~h}$ to PWR primary simulated media have been well characterized by TEM in a previous study ${ }^{[12]}$. It has been showed that the oxide scale is at least composed of 3 oxides: nickel ferrite, iron and nickel mixed chromite and discontinuous nodules of chromia along the oxide/alloy interface. As metallic contributions are not evidenced on figures 5(d) and 6(d), it can be supposed that chromia is too deep in the oxide scale to be measured by XPS, leading to the conclusion that the contribution of the oxidized chromium emphasized on figure 5(d) is due to the presence of chromite in the oxide scale. Therefore, the peak at $856.3 \mathrm{eV}$ on the $\mathrm{Ni}-2 p_{3 / 2}$ core level (figure 6(d)) seems to be also partially due to the presence of chromite. The height ratio of the satellite to the $856.3 \mathrm{eV}$ peak is equal to 0.61, which is close to the value reported for $\mathrm{NiCr}_{2} \mathrm{O}_{4}$ in subsection 3-1-1, but not high enough to exclude the presence of nickel hydroxide from the corrosion products layer. Even if the contribution of lattice oxide is the main one, the appearance of two minor peak components at roughly $531.5 \mathrm{eV}$ and $533.5 \mathrm{eV}$ on the $\mathrm{O}-1 \mathrm{~s}$ core level spectrum (figure 7(d)) may be in agreement with the presence of hydrated nickel hydroxide but could be also the consequence of the sample contamination.

The comparison of core level spectra recorded on alloy 690 corroded samples to reference data discussed in subsection 3-1 leads to several remarks. The deconvolution of $\mathrm{Cr}-2 p_{3 / 2}$ core level spectra seem to show that the internal oxide scale growing on alloy 690 exposed to PWR primary simulated medium is made of a mix of chromite and chromia.

Moreover, the interpretation of $\mathrm{Ni}-2 p_{3 / 2}$ spectra highlights some key points about the external oxide layer. The height ratio between satellite and principal peaks on the $\mathrm{Ni}-2 p_{3 / 2}$ core level seems to be useful in order to characterize a mix of nickel-containing corrosion products. In this study, this parameter allows evidencing the presence of nickel hydroxide whatever the corrosion duration, while previous works led by TEM ${ }^{[12]}$ or PEC ${ }^{[13]}$, on the same samples, have not permitted to obtain this result. The presence of this hydroxide in the external layer seems to be also corroborated by the deconvolution of O- $1 s$ spectra. 
The fit of the Ni- $2 p_{3 / 2}$ core level seems to permit equally the highlighting of nickel ferrite precipitation.

Nevertheless, a slight difference in the principal peak BE is evidenced between the case of corrosion products formed on alloy 690 and the $\mathrm{NiFe}_{2} \mathrm{O}_{4}$ reference spectrum $(855.0 \mathrm{eV}$ and $855.3 \mathrm{eV}$ respectively). As discussed above, the minor peaks emphasized on $\mathrm{NiCr}_{2} \mathrm{O}_{4}$ reference spectra are also not yet evidenced on spectra recorded on oxidized alloy 690 samples. These could be some consequences of the difference in composition between reference compounds and the ferrite and chromite effectively formed on alloy 690, in which $\mathrm{Fe}$ is partially substituted to $\mathrm{Ni}^{[11-13]}$. To clarify this point, the effect of $\mathrm{Ni}$ substitution by $\mathrm{Fe}$ on the shape of $\mathrm{Ni}-2 p_{3 / 2}$ core level need to be investigated on reference compounds of $\mathrm{Ni}_{(1-}$ z) $\mathrm{Fe}_{(2+z)} \mathrm{O}_{4}$ and $\mathrm{Ni}_{(1-\mathrm{x})} \mathrm{Fe}_{\mathrm{x}} \mathrm{Cr}_{2} \mathrm{O}_{4}$, for different $\mathrm{z}$ and $\mathrm{x}$ values. The lack of such reference data does not allow at the present time any more accurate deconvolution of $\mathrm{Ni}-2 p_{3 / 2}$ core level spectra, in the case of corrosion products formed on alloy 690 exposed to PWR primary media.

\section{3-2-2- Evidencing of the precipitation of nickel ferrite by XPS}

The precipitation of nickel ferrite during the corrosion process of the alloy 690 in PWR primary environment lead to the formation of well-defined octahedral crystals, which can be easily evidenced by SEM observations ${ }^{[5-7,12]}$. Nevertheless, XPS can be useful in order to study the kinetics of this precipitation, because it allows for a mean quantification, although relative, at a scale (roughly $1 \mathrm{~mm}^{2}$ ) which is consistent with the description of generalized corrosion phenomena. The aim of this subsection is to verify if variations in the $855.0 \mathrm{eV}$ peak intensity (observed on the $\mathrm{Ni}-2 p_{3 / 2}$ core level of alloy 690 corroded samples) can be correlated with those of the nickel ferrite quantity.

SEM observations carried out on alloy 690 samples exposed to PWR primary medium for different durations are reported in figure 8. Optimal working conditions of the ion-exchange resins during corrosion tests (see subsection 2-2-2) result in the presence of only few crystallites of nickel ferrite on the surface of samples, as seen on micrographs recorded after $24 \mathrm{~h}$ and $406 \mathrm{~h}$ exposures (figures $8(\mathrm{a})$ and $8(\mathrm{~b})$ ). When the recirculation loop is monitoring under "damaged conditions", figures 8(c) and 8(d), a large increase of both numbers of crystallites per surface unit and crystallite size are observed. The precipitation of $\mathrm{Ni}_{(1-}$ z) $\mathrm{Fe}_{(2+z)} \mathrm{O}_{4}$ is then strongly linked to the efficiency of ion-exchange resins, but seems to be also bound to immersion time, when comparing figures 8 (a) to 8 (b) and $8(\mathrm{c})$ to $8(\mathrm{~d})$.

The relative evolutions of the intensity of the contribution at $855.0 \mathrm{eV}$ on the $\mathrm{Ni}-2 p_{3 / 2}$ spectra and the Fe- $2 p_{1 / 2}$ complete area, for all investigated immersion times, are reported on figure 9. There are in good agreement with SEM observations: the two exposure times which exhibit the maximum proportions of both contributions correspond to the damaged working conditions, corroborating that the precipitation of nickel ferrite is emphasized during such experiments. These results highlight the relationship between the concentration of $\mathrm{Fe}$ and $\mathrm{Ni}$ cations in the media and the growth of the external oxide layer as previously evidenced in a former work ${ }^{[12]}$.

However, it can be pointed out that the complete area of the Fe- $2 p_{1 / 2}$ is not only linked to ferrite precipitation, but that part of this area is necessarily due to the iron contained in the alloy and in the internal oxide scale (mainly made of $\mathrm{Ni}_{(1-\mathrm{x})} \mathrm{Fe}_{\mathrm{x}} \mathrm{Cr}_{2} \mathrm{O}_{4}$ ). In contrast, the variations in the $855.0 \mathrm{eV}$ peak intensity seem to be useful for studying the kinetics of ferrite precipitation, even if the detection limit of this phenomenon is lower by XPS than by SEM 
(on figure 8(a), few crystallites were observed while no ferrite-associated peak was evidenced on the corresponding $\mathrm{Ni}-2 p_{3 / 2}$ spectra).

\section{4- Conclusions}

The aim of this work was to evaluate the contribution of XPS analyses to the description of oxide scales formed on nickel base alloys exposed to PWR primary media, having been previously characterized by SEM, TEM and PEC.

Those corrosion layers are made of a mixture of oxides and hydroxides and the deconvolution of $\mathrm{Cr}-2 p_{3 / 2}, \mathrm{Ni}-2 p_{3 / 2}$ and $\mathrm{O}-1 s$ core level recorded on such samples need to preliminarily perform spectra on reference compounds.

Indeed, the comparison of data collected in the literature and reference spectra performed in this work seems to evidence that core level fits are dependent of the energy resolution which can be achieved with specific spectrometer and analysis procedures. A lack in reference data, recorded under the same analytical configuration, could lead to confusing issues when a mixture of corrosion products is analyzed.

The comparison of core level spectra recorded on alloy 690 corroded samples and reference compounds lead to several conclusions.

(i) The deconvolution of $\mathrm{Cr}-2 p_{3 / 2}$ core level spectra suggests that the internal oxide scale is made of a mix of chromite and chromia.

(ii) The study of the evolution of the height ratio, between satellite and principal peaks, on the $\mathrm{Ni}-2 p_{3 / 2}$ core level has highlighted the presence of nickel hydroxide for all the corrosion durations. This result has not yet been clearly evidenced by TEM or PEC characterizations carried out during former studies using this same set of samples.

(iii) The precipitation of nickel ferrite during the corrosion process can be evidenced by the variations in intensity of a peak located at a BE of $855.0 \mathrm{eV}$ on the $\mathrm{Ni}-2 p_{3 / 2}$ core level. Such variations allow using XPS analyses to study the kinetics of this phenomenon, with a measure performed on roughly $1 \mathrm{~mm}^{2}$ : $i . e$. at a scale which is consistent with the description of generalized corrosion phenomena.

It must be emphasized that, even if this XPS study brings complementary elements to those obtained in our previous works, a more complete description of these oxide scales seems to be achieved, through the use of better adapted reference compounds. Indeed, in nickel ferrite and chromite formed on Ni base alloys exposed to PWR primary medium, Fe is partially substituted to $\mathrm{Ni}$. The use of reference compounds of $\mathrm{Ni}_{(1-\mathrm{z})} \mathrm{Fe}_{(2+\mathrm{z})} \mathrm{O}_{4}$ and $\mathrm{Ni}_{(1-\mathrm{x})} \mathrm{Fe}_{\mathrm{x}} \mathrm{Cr}_{2} \mathrm{O}_{4}$, with different $\mathrm{z}$ and $\mathrm{x}$ values, could improve the oxide scale description based on XPS results. 


\section{References}

[1] A. Machet, A. Galtayries, S. Zanna, L. Klein, V. Maurice, P. Jolivet, M. Foucault, P. Combrade, P. Scott, P. Marcus, Electrochim. Acta 2004 ; 49, 3957.

[2] N. S. McIntyre, D. G. Zetaruk, D. Oven , J. Electrochem. Soc. 1979 ; 126 , 750.

[3] T. M. Angeliu, G. S. Was, J. Electrochem. Soc. 1993 ; 140 , 1877.

[4] A. Machet, A. Galtayries, P. Jolivet, M. Foucault, P. Combrade, P. Scott, P. Marcus Corrosion issues in light water reactors: Stress corrosion cracking (Eds. D. Féron, J.-M. Olive) Woodhead Publishing Limited, Cambridge, 2007, pp. 44-56.

[5] A. Machet, A. Galtayries, P. Marcus, P. Combrade, P. Jolivet, P. Scott, Surf. Interface Anal. 2002 ; $34,197$.

[6] F. Carrette, M. C. Lafont, G. Chatainier, L. Guinard, B. Pieraggi, Surf. Interface Anal. $2002 ; 34,135$.

[7] F. Carrette, M. C. Lafont, L. Legras, L. Guinard, B. Pieraggi, Mater. High Temp. 2003 ; 20,581 .

[8] C. Soustelle, M. Foucault, P. Combrade, K. Wolski, T. Magnin, Proceedings of the Ninth International Symposium on Environmental Degradation of Materials in Nuclear Power Systems - Water Reactors (Eds F.P. Ford, S. M. Bruemmer, G. S. Was), The Minerals, Metals and Material Society (TMS), Warrendale, 1999, pp. 105-113.

[9] F. Delabrouille, B. Viguier, L. Legras, E. Andrieu, Mat. High. Temp. 2005 ; 22 , 287.

[10] J. Panter, B. Viguier, J.-M. Cloué, M. Foucault, P. Combrade, E. Andrieu, J. Nucl. Mater. 2006 ; $348,213$.

[11] M. Sennour, L. Marchetti, S. Perrin, M. Pijolat, O. Raquet, Mater. Sci. Forum 2008 ; $595-598,539$.

[12] M. Sennour, L. Marchetti, F. Martin, S. Perrin, R. Molins, M. Pijolat, J. Nucl. Mater. $2010 ; 402,147$.

[13] L. Marchetti, S. Perrin, Y. Wouters, F. Martin, M. Pijolat, Electrochim. Acta 2010 ; 55 , 5384 .

[14] F. Carrette, L. Guinard, B. Pieraggi, Proceedings of the International conference on water chemistry in reactors systems, Avignon, France, 2002.

[15] H. Lefaix-Jeuland, L. Marchetti, S. Perrin, M. Pijolat, M. Sennour, R. Molins, Corros. Sci. $2011 ; 53$, 3914.

[16] L. Guinard, O. Kerrec, D. Noel, S. Gardey, F. Coulet, Nucl. Energy 1997 ; 36 , 19.

[17] L. Marchetti, S. Perrin, O. Raquet, M. Pijolat, Mater. Sci. Forum 2008 ; 595-598, 529. 
[18] N. S. McIntyre, M. G. Cook, Anal. Chem. 1975 ; 47 , 2208.

[19] N. S. McIntyre, D. G. Zetaruk, D. Oven, Appl. Surf. Sci. 1978 ; 2 , 55.

[20] A. P. Grosvenor, M. C. Biesinger, R. St. C. Smart, N. S. McIntyre, Surf. Sci. 2006 ; 600 , 1771 .

[21] A. R. Pratt, N. S. McIntyre, Surf. Interface Anal. 1996 ; 24 , 529.

[22] M. C. Biesinger, C. Brown, J. R. Mycroft, R. D. Davidson, N.S. McIntyre, Surf. Interface Anal. $2004 ; 36,1550$.

[23] B. Beverskog, I. Puigdomenech, Corros. Sci. 1997 ; 39 , 969.

[24] M. C. Biesinger, B. P. Payne, L. W. M. Lau, A. Gerson, R. St. C. Smart, Surf. Interface Anal. 2009 ; $41,324$.

[25] M. C. Biesinger, B. P. Payne, A. P. Grosvenor, L. W. M. Lau, A. R. Gerson, R. St. C. Smart, Appl. Surf. Sci. 2011 ; $257,2717$.

[26] M. Lenglet, A. d'Huysser, J. Arsène, J. P. Bonnelle, C. K. Jørgensen, J. Phys. C: Solid State Phys. 1986 ; 19 , L363.

[27] J. Sloczynski, J. Ziolkowski, B. Grzybowska, R. Grabowski, D. Jachewicz, K. Wcislo, L. Gengembre, J. Catal. 1999 ; 187 , 410.

[28] A. Machet, Etude des premiers stades d'oxydation d'alliages inoxydables dans l'eau à haute température, $\mathrm{PhD}$ thesis, Université Pierre et Marie Curie, Paris, France, 2004.

[29] A. N. Mansour, Surf. Sci. Spectra 1996 ; 3 , 239.

[30] A. N. Mansour, C. A. Melendres, Surf. Sci. Spectra 1996 ; 3 , 255.

[31] A. N. Mansour, C. A. Melendres, Surf. Sci. Spectra 1996 ; 3 , 247.

[32] G. P. Halada, C. R. Clayton, , J. Electrochem. Soc. 1991 ; 38, 2921.

[33] I. Grohmann, E. Kemnitz, A. Lippitz, W. E. S. Unger, Surf. Interface Anal. 1995 ; 23 , 887.

[34] R. P. Gupta, S. K. Sen, Phys. Rev. B 1974 ; 10 , 71.

[35] R. P. Gupta, S. K. Sen, Phys. Rev. B 1975 ; 12 , 15.

[36] H. A. E. Hagelin-Weaver, J. F. Weaver, G. B. Hoflund, G. N. Salaita, , J. Electron. Spectrosc. Relat. Phenom. $2004 ; 134,139$.

[37] A. P. Grosvenor, B. A. Kobe, N. S. McIntyre, Surf. Sci. 2004 ; 572 , 217 
Tables

\begin{tabular}{|cccccccccccc|}
\hline $\mathrm{Ni}$ & $\mathrm{Cr}$ & $\mathrm{Fe}$ & $\mathrm{C}$ & $\mathrm{Co}$ & $\mathrm{Mn}$ & $\mathrm{Al}$ & $\mathrm{Ti}$ & $\mathrm{Cu}$ & $\mathrm{Si}$ & $\mathrm{S}$ & $\mathrm{P}$ \\
\hline 59.31 & 29.20 & 9.94 & 0.018 & 0.014 & 0.31 & 0.13 & 0.27 & $<0.002$ & 0.27 & $<0.0005$ & 0.007 \\
\hline
\end{tabular}

Table 1: Composition (in wt\%) of alloy 690

\begin{tabular}{|c|c|c|c|c|c|}
\hline Compounds & $\begin{array}{c}\text { BE for Peak } 1 \\
(\mathrm{eV}) \\
\text { ta\% }\end{array}$ & $\begin{array}{c}\text { BE for Peak } 2 \\
(\mathrm{eV}) \\
t a \%\end{array}$ & $\begin{array}{c}\text { BE for Peak } 3 \\
(\mathrm{eV}) \\
\text { ta\% }\end{array}$ & $\begin{array}{c}\text { BE for Peak } 4 \\
(\mathrm{eV}) \\
t a \%\end{array}$ & $\begin{array}{c}\text { BE for Peak } 5 \\
(\mathrm{eV}) \\
\text { ta\% }\end{array}$ \\
\hline \multirow{2}{*}{$\mathrm{Cr}_{2} \mathrm{O}_{3}$} & 575.9 & 576.9 & 577.7 & 578.7 & 579.1 \\
\hline & 36 & 35 & 19 & 8 & 5 \\
\hline \multirow{2}{*}{$\mathrm{NiCr}_{2} \mathrm{O}_{4}$} & 575.4 & 576.4 & 577.2 & 578.3 & 579.4 \\
\hline & 35 & 34 & 18 & 9 & 4 \\
\hline \multirow{2}{*}{$\mathrm{FeCr}_{2} \mathrm{O}_{4}$} & 576.1 & 577.2 & 578.1 & 579.1 & \multirow[b]{2}{*}{ - } \\
\hline & 41 & 39 & 13 & 7 & \\
\hline
\end{tabular}

Table 2: Binding energies (BE) and contributions of the associated peak to the total area of the core level envelope ( $t a \%$ ), for the fit of the $\mathrm{Cr} 2 \mathrm{p}_{3 / 2}$ spectra of $\mathrm{Cr}_{2} \mathrm{O}_{3}, \mathrm{NiCr}_{2} \mathrm{O}_{4}$ and $\mathrm{FeCr}_{2} \mathrm{O}_{4}$, from Biesinger et al. [25] 


\section{Figures captions}

Figure 1: Schematic view of the oxide scale that forms during the exposition of Ni base alloys in PWR primary water [11-13].

Figure 2: Curve fitted Ni-2 $p_{3 / 2}$ spectra of reference (a) metallic $\mathrm{Ni}$; (b) $\mathrm{NiFe}_{2} \mathrm{O}_{4}$; (c) $\mathrm{NiCr}_{2} \mathrm{O}_{4}$ and $(\mathrm{d}) \mathrm{Ni}(\mathrm{OH})_{2}$ compounds.

Figure 3: Curve fitted Cr-2 $2 p_{3 / 2}$ spectra of reference (a) $\mathrm{Cr}_{2} \mathrm{O}_{3}$ and (b) $\mathrm{NiCr}_{2} \mathrm{O}_{4}$ compounds.

Figure 4: Curve fitted O- $1 s$ spectra of reference (a) $\mathrm{Cr}_{2} \mathrm{O}_{3}$; (b) $\mathrm{NiFe}_{2} \mathrm{O}_{4}$; (c) $\mathrm{NiCr}_{2} \mathrm{O}_{4}$ and (d) $\mathrm{Ni}(\mathrm{OH})_{2}$ compounds.

Figure 5: Curve fitted Cr- $2 p_{3 / 2}$ spectra of alloy 690 corroded at different exposure times in PWR primary coolant conditions.

Figure 6: Curve fitted Ni-2 $2 p_{3 / 2}$ spectra of alloy 690 corroded at different exposure times in PWR primary coolant conditions.

Figure 7: Curve fitted O- $1 s$ spectra of alloy 690 corroded at different exposure times in PWR primary coolant conditions.

Figure 8: SEM observations of the surface of alloy 690 after different exposure times and for different ion-exchange resin working conditions: (a-b) exposed to PWR primary simulated water at optimized working conditions, for $24 \mathrm{~h}$ (a) and $406 \mathrm{~h}$ (b); (c-d) exposed to PWR primary simulated water in "damaged conditions", for $164 \mathrm{~h} \mathrm{(c)} \mathrm{and} 858 \mathrm{~h}(\mathrm{~d})$.

Figure 9: Evolution of the proportion associated to the $\mathrm{Fe}-2 p_{1 / 2}$ and nickel ferrite $\mathrm{Ni}-2 p_{3 / 2}$ peaks as function of the immersion time of alloy 690 in PWR primary medium at $325^{\circ} \mathrm{C}$. 
Figure 1

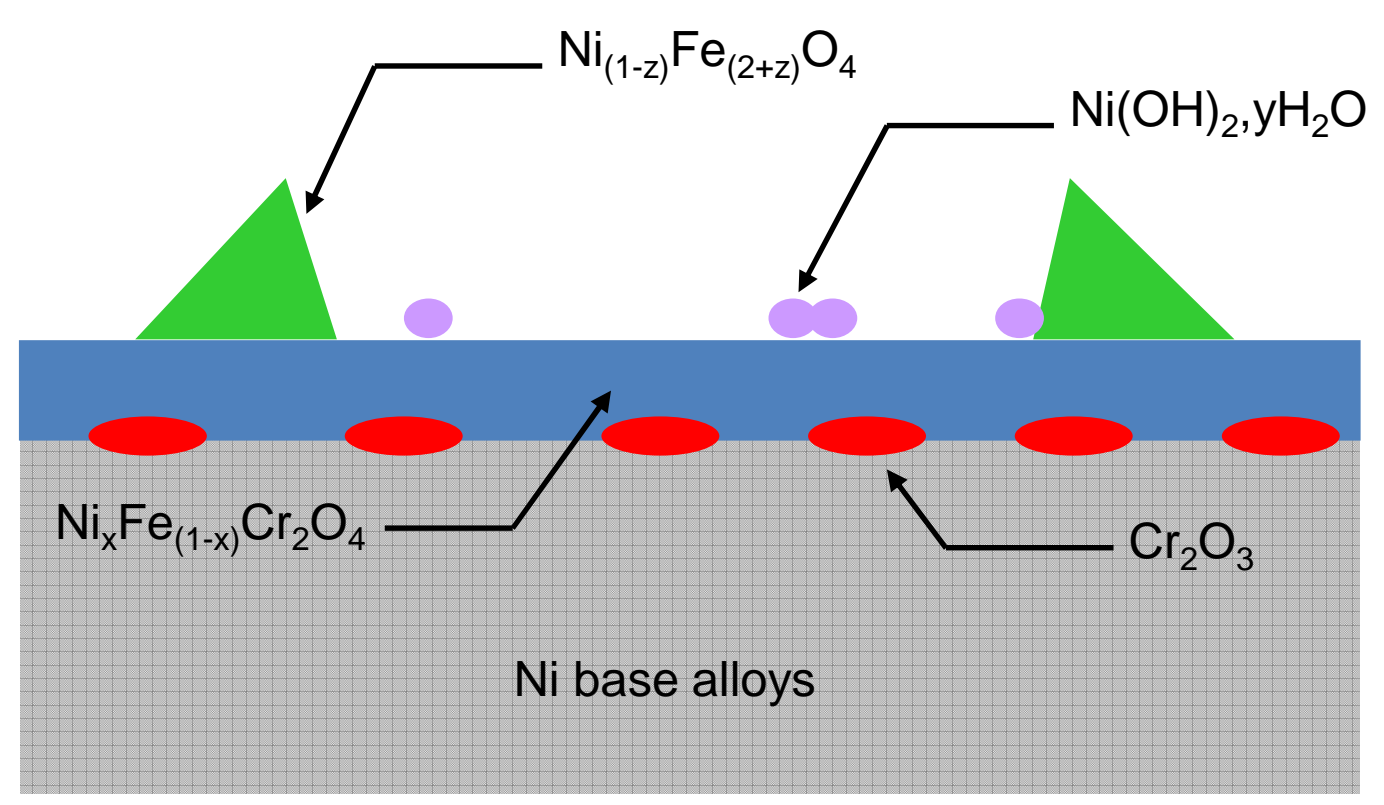


Figure 2




Figure 3

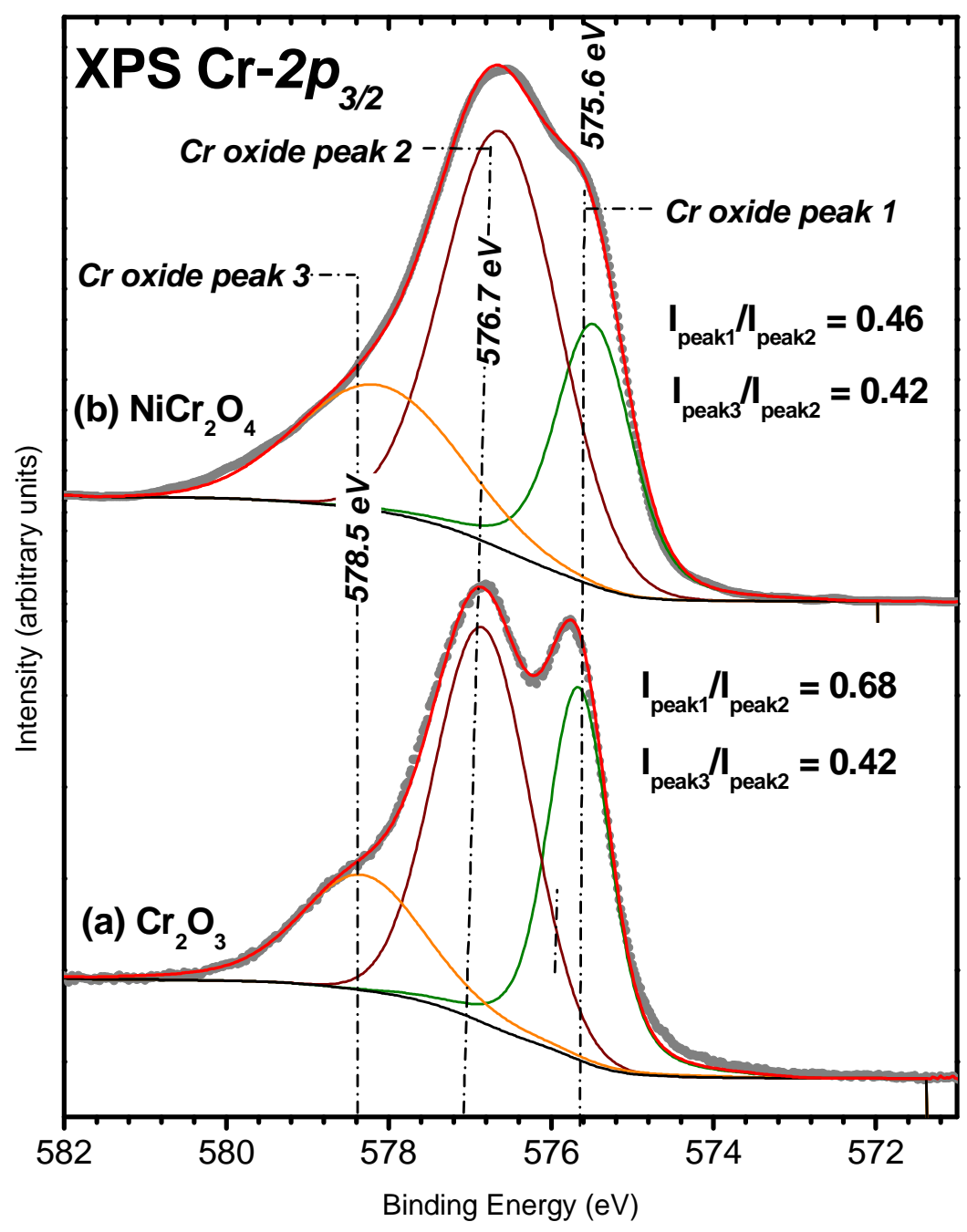


Figure 4

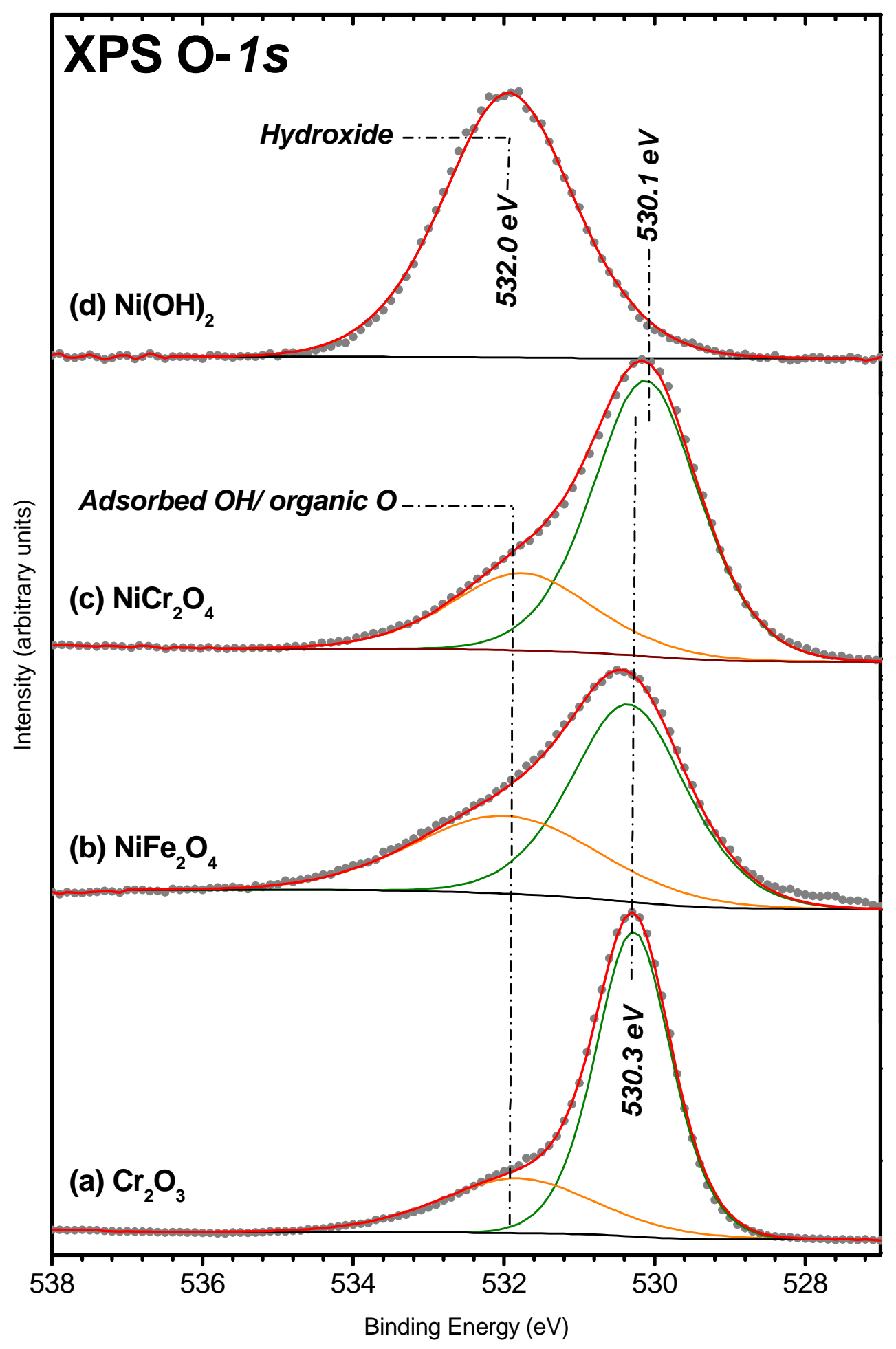




\section{Figure 5}

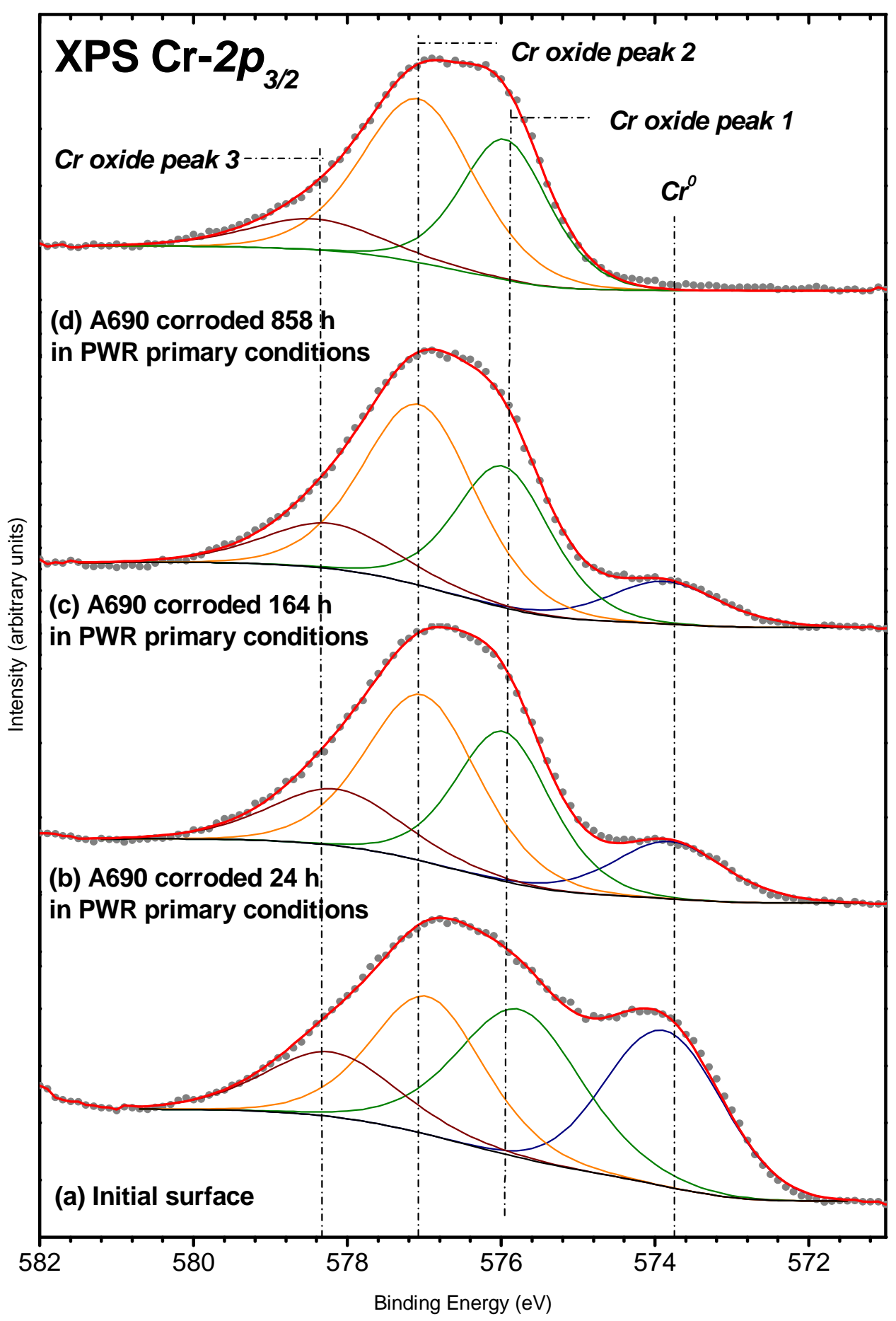


Figure 6

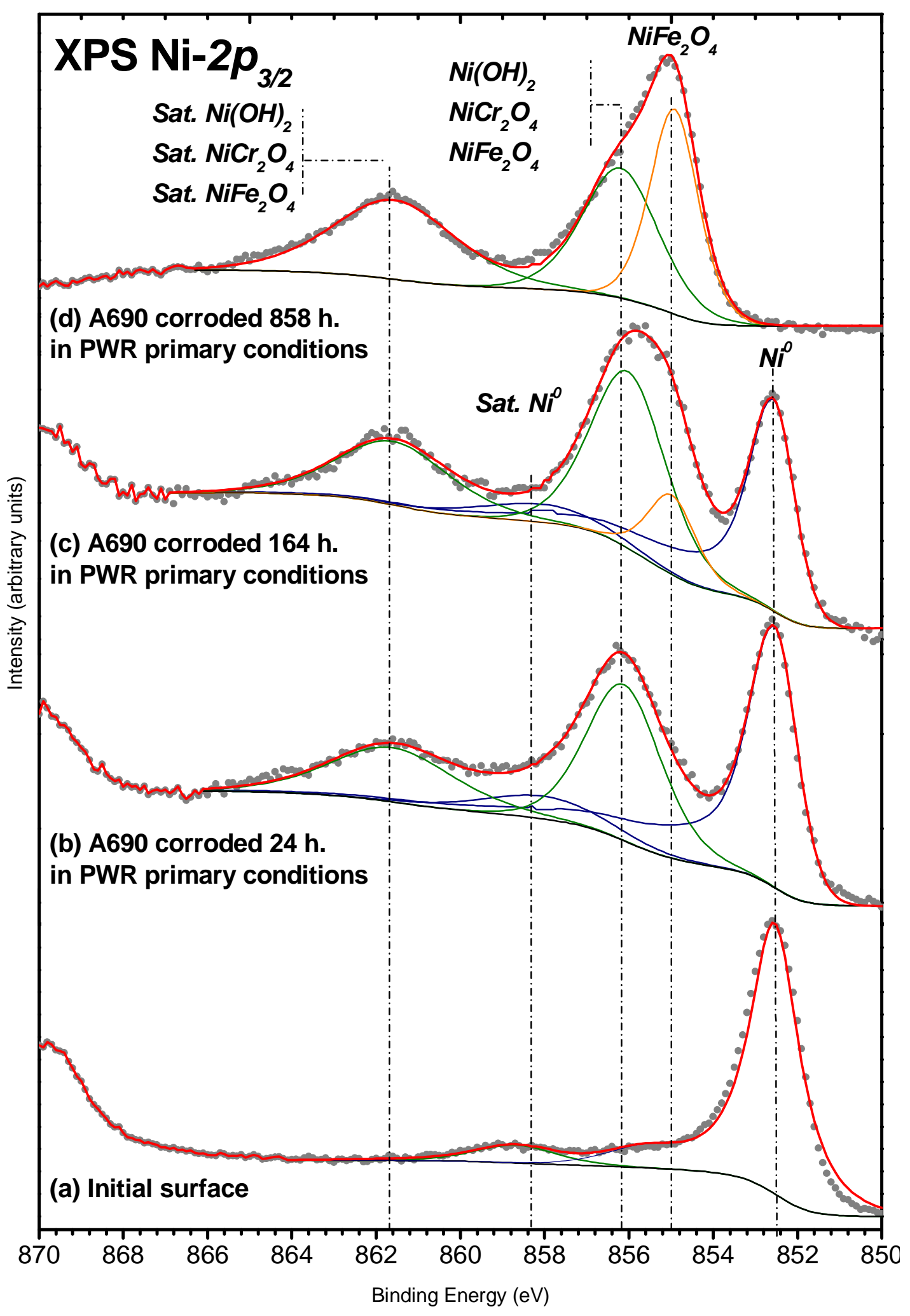


Figure 7

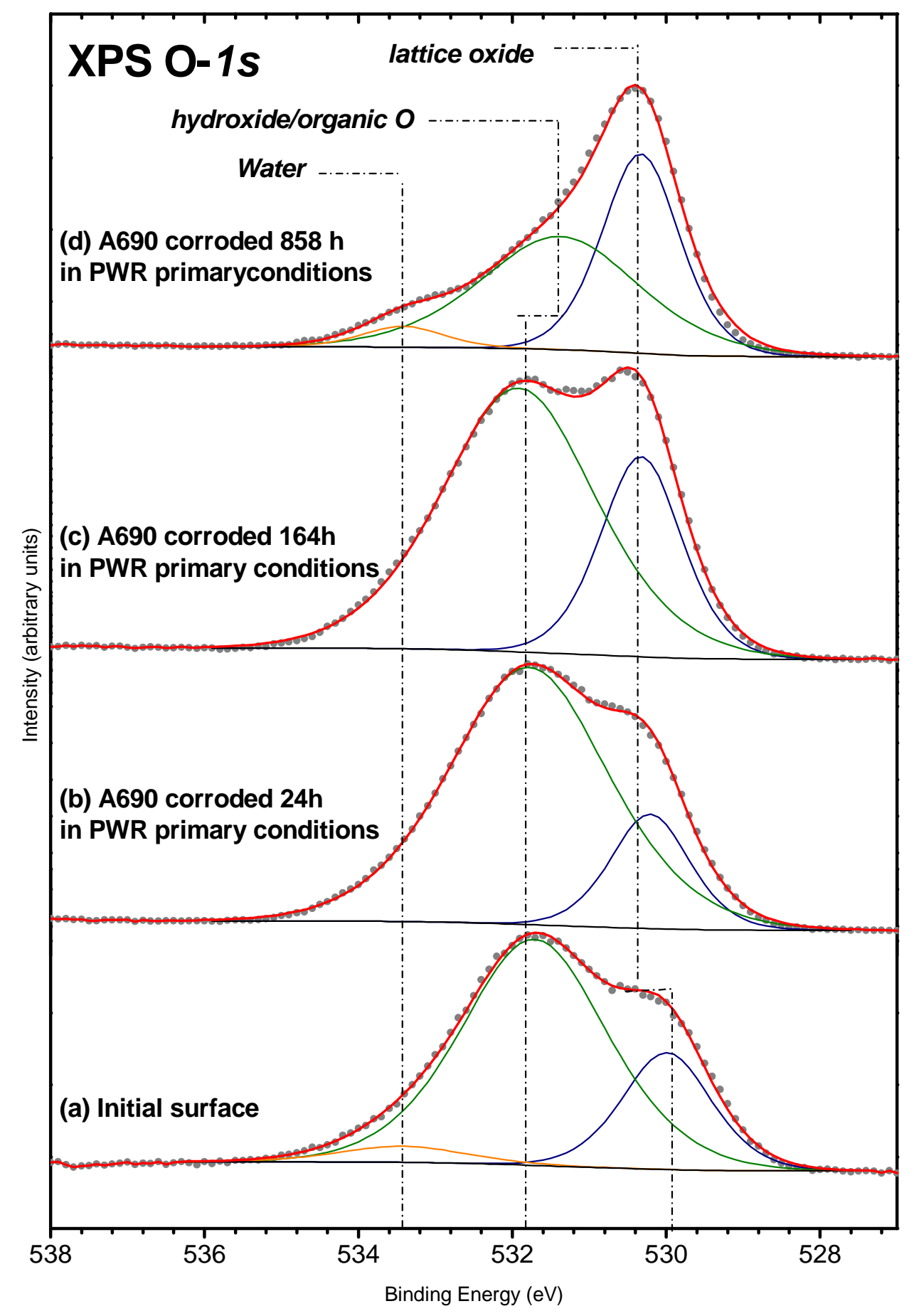


Figure 8
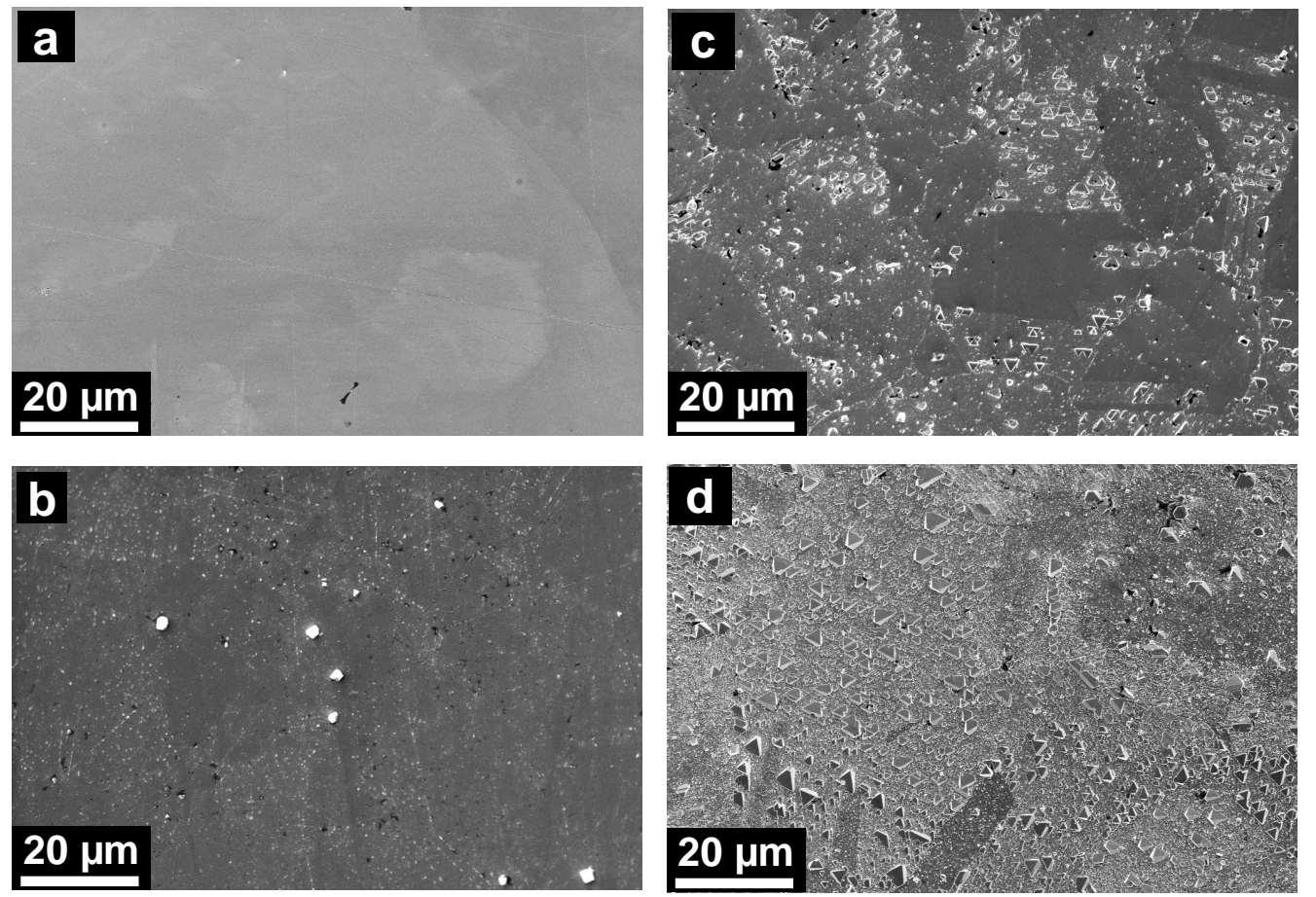


\section{Figure 9}

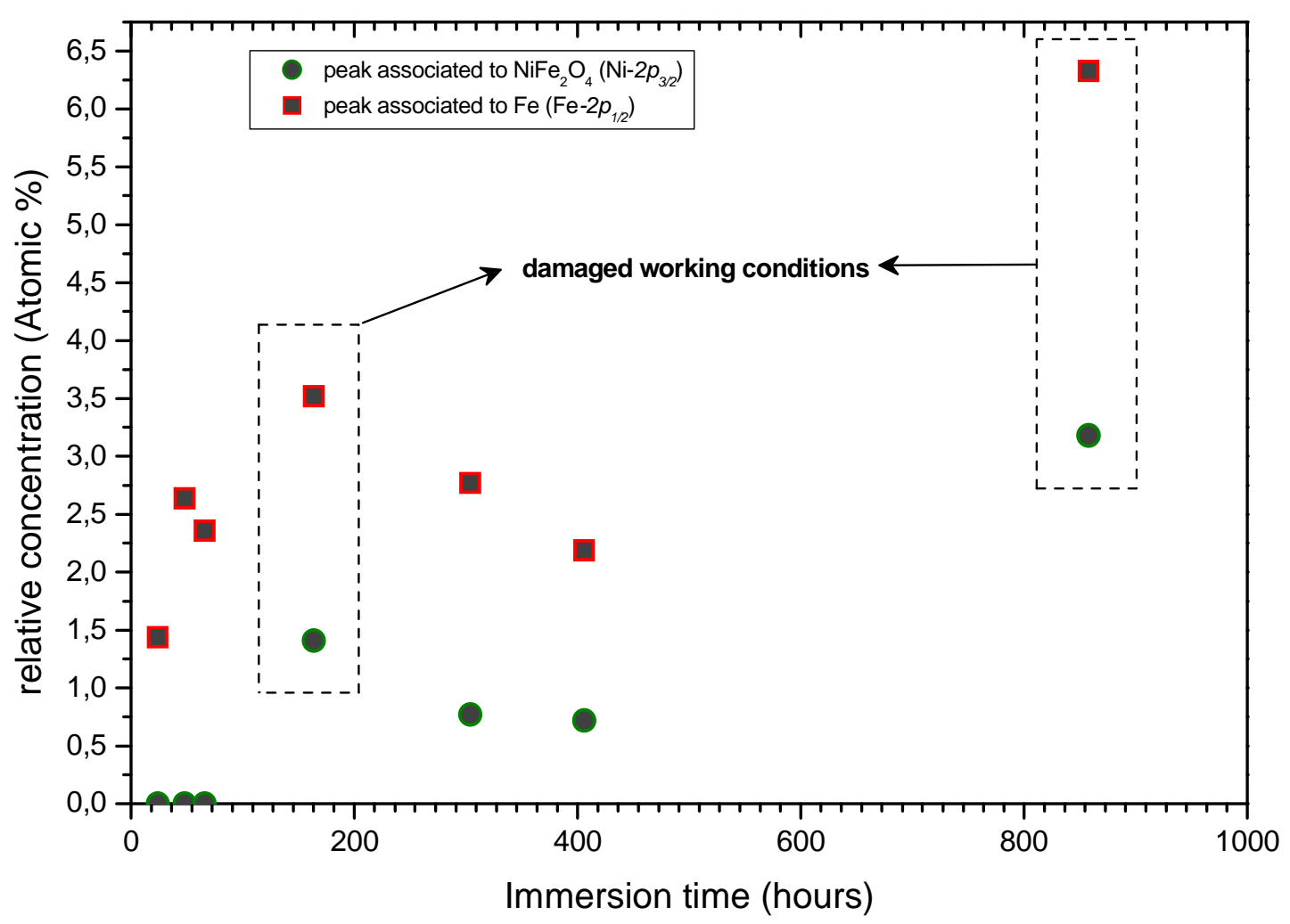

